\title{
Impacts of seasonality and nutrients on microbial mat community structure and function
}

\author{
J. Pinckney, H. W. Paerl, M. Fitzpatrick \\ University of North Carolina at Chapel Hill, Institute of Marine Sciences, 3431 Arendell Street, Morehead City, \\ North Carolina 28557, USA
}

\begin{abstract}
To understand the mechanisms responsible for seasonal fluctuations in growth and $\mathrm{N}_{2}$ fixation in intertidal microbial mat communties, we quantified seasonal changes in mat community composition, related these changes to diel and seasonal $\mathrm{N}_{2}$ fixation rates, and evaluated community responses (growth, $\mathrm{N}_{2}$ fixation, composition) to long-term (22 d) nutrient addition bioassays. A temperate intertidal cyanobacterial mat community, located in coastal North Carolina, USA, was sampled at monthly intervals for 1 yr (1993-94) to determine changes in community composition. The abundances of major phototrophic groups were quantified based on the relative concentrations of taxaspecific photopigments (chlorophylls and carotenoids). The most abundant phototrophs were cyanobacteria, diatoms, and photosynthetic bacteria. Mat biomass and community composition underwent marked changes on both monthly and seasonal scales and corresponded with seasonal shifts in the diel patterns of $\mathrm{N}_{2}$ fixation. Diatom biomass increased during periods of low $\mathrm{N}_{2}$ fixation. Nutrient (nitrate and phosphatel addition bioassays indicated that both cyanobacterial and diatom growth were $\mathrm{N}$ limited. Cyanobacteria were able to circumvent $\mathrm{N}$ limitation by $\mathrm{N}_{2}$ fixation. The addition of high concentrations of $\mathrm{N}\left(100 \mu \mathrm{M} \mathrm{NaNO}_{3}\right)$ in combination with $\mathrm{P}\left(100 \mu \mathrm{M} \mathrm{NaH}_{2} \mathrm{PO}_{4}\right)$ resulted in an increase $(163 \%)$ in the relative abundance of diatoms. The addition of $\mathrm{P}$ alone more than doubled $\mathrm{N}_{2}$ fixation rates and cyanobacterial abundance increased $(+34 \%)$ relative to diatoms. However, $\mathrm{N}$ and NP additions significantly lowered (by more than $75 \%$ ) $\mathrm{N}_{2}$ fixation rates. Here we show that manipulative experiments, together with quantitative assessments of community composition based on chemotaxonomic pigments, can provide useful insights into the mechanisms that relate mat community structure and function to environmental constraints, including nutrient limitation and seasonal climatic changes.
\end{abstract}

KEY WORDS: Cyanobacteria $\cdot$ Microbial mat $\cdot$ Microphytobenthos $\cdot \mathrm{HPLC} \cdot \mathrm{N}_{2}$ fixation $\cdot$ Competition Nutrient

\section{INTRODUCTION}

Microbial mats are laminated microbial communities that form interdependent layers of vertically stratified heterotrophic, chemoautotrophic, and photoautotrophic microorganisms on the surface of sediments in marine and estuarine habitats (Whitton \& Potts 1982 , Stal et al. 1985). The mixed assemblage of oxygenic and anoxygenic phototrophs in mats use seasonally variable resources (e.g. light and nutrients) that may influence the relative abundances of community components (Jørgensen \& Des Marais 1988, Fong et al. 1993). However, we know little about how mat phototrophic community structure shifts in response to seasonal changes and how these changes are related to community function (growth and $\mathrm{N}_{2}$ fixation). Quan- tification of mat community composition by direct microscopy is impractical for ecologically relevant and statistically valid sample sizes. However, mat functional groups can be quickly and quantitatively assessed using photosynthetic pigments as biomarkers.

Photosynthetic pigments (chlorophylls and carotenoids) may be used as chemotaxonomic (taxa-specific) indicators of the relative abundance of major taxonomic groups and provide a means for assessing changes in the relative abundance of phototroph functional groups (Gieskes 1991, Klein \& Riaux-Gobin 1991, Wilhelm et al. 1991, Millie et al. 1993). For microbial mats, the major diagnostic photopigments are chlorophyll a (all oxygenic phototrophs), zeaxanthin (cyanobacteria), fucoxanthin (diatoms), and bacteriochlorophyll a (anoxygenic phototrophs, mainly purple 
sulfur bacteria) (Palmisano et al. 1989a, b, Rowan 1989, Millie et al. 1993). The molar ratio of zeaxanthin to fucoxanthin (zeax/fuco) may be used as an indicator of the abundance of cyanobacteria relative to diatoms. When measured over time, zeax/fuco shows relative changes in microbial mat community composition.

Previous work on intertidal cyanobacterial mat communities in coastal North Carolina, USA, implicated nonheterocystous cyanobacteria as the diazotrophs responsible for the observed high rates of $\mathrm{N}_{2}$ fixation (Bebout et al. 1993). Seasonal patterns of cyanobacterial biomass and $\mathrm{N}_{2}$ fixation potentials showed a distinct positive relationship. Generally, the highest rates of total daily $\mathrm{N}_{2}$ fixation occurred in the summer when cyanobacterial biomass was high (Bebout et al. 1987, 1993, Paerl et al. 1993). These mats exhibited a diel variability in $\mathrm{N}_{2}$ fixation with nighttime rates 3 - to 10 fold higher than daytime rates during the summer (Bebout et al. 1993). During winter, most $N_{2}$ fixation occurred in daylight, but rates were much lower than during the summer.

The ability of cyanobacterial mat communities to supplement $N$ requirements via localized regeneration and $\mathrm{N}_{2}$ fixation, coupled with their wide distribution in oligotrophic waters, suggests that these communities do not strongly depend on exogenous $N$ sources for growth. Given these circumstances, one wonders whether cyanobacterial mat communities are ever nutrient-limited. Several studies have addressed this question by examining growth and $\mathrm{N}_{2}$ fixation responses following nutrient (nitrate and phosphate) additions (Paerl et al. 1993). In most cases, nutrient addition bioassays failed to demonstrate nutrient limitation. However, in these bioassays, mats were only exposed to the nutrient additions for periods ranging from 1 to $5 \mathrm{~d}$. Paerl et al. (1993) suggested that, due to low growth rates, these short-term incubation periods may not have been sufficiently long to allow measurable changes in biomass and $\mathrm{N}_{2}$ fixation.

To understand the mechanisms responsible for seasonal fluctuations in the emergent properties (i.e. growth and $\mathrm{N}_{2}$ fixation) of intertidal microbial mat communities, we must first determine how the dominant 'players' in the community respond to changes in environmental conditions. This may be possible if responses to environmental changes are examined over long (i.e. $>1$ to $5 \mathrm{~d}$ ) time intervals. The purpose of this study was to determine the seasonal changes in microbial mat community composition, relate these changes to diel and seasonal $\mathrm{N}_{2}$ fixation rates, and evaluate community responses (growth, $\mathrm{N}_{2}$ fixation, and community composition) to longer-term (22 d) nutrient addition bioassays.

\section{MATERIALS AND METHODS}

Study site. Bird Shoal $\left(34.7^{\circ} \mathrm{N}, 76.7^{\circ} \mathrm{W}\right)$ is a sandy tidal flat on the southern side of a dredge spoil island (Carrot Island) in the Rachel Carson National Estuarine Research Reserve near Beaufort, North Carolina, USA (Fig. 1). Microbial mats inhabit the upper intertidal zone in a mosaic interspersed with bare sand patches. Mat orientation is associated with the degree of exposure to high wave energy generated periodically by strong southerly and southwesterly winds. Large sections of mat are frequently displaced when strong winds and high tides coincide. The mat photosynthetic community is composed primarily of the filamentous, nonheterocystous cyanobacteria Microcoleus chthonoplastes, Lyngbya aestuari, and Oscillatoria spp. Benthic diatoms (motile and attached species) inhabit the interstitial and surface layers of the mat. Purple sulfur bacteria (primarily Chromatium) form a thin layer at the oxic/anoxic interface. Colorless sulfur bacteria (primarily Beggiatoa) are occasionally abundant and migrate to the surface of the mat during the night. Bare sand patches are dominated by a mixed assemblage of epipelic and epipsammic diatoms.

Seasonal changes in community composition. Four sampling sites were selected at Bird Shoal and marked

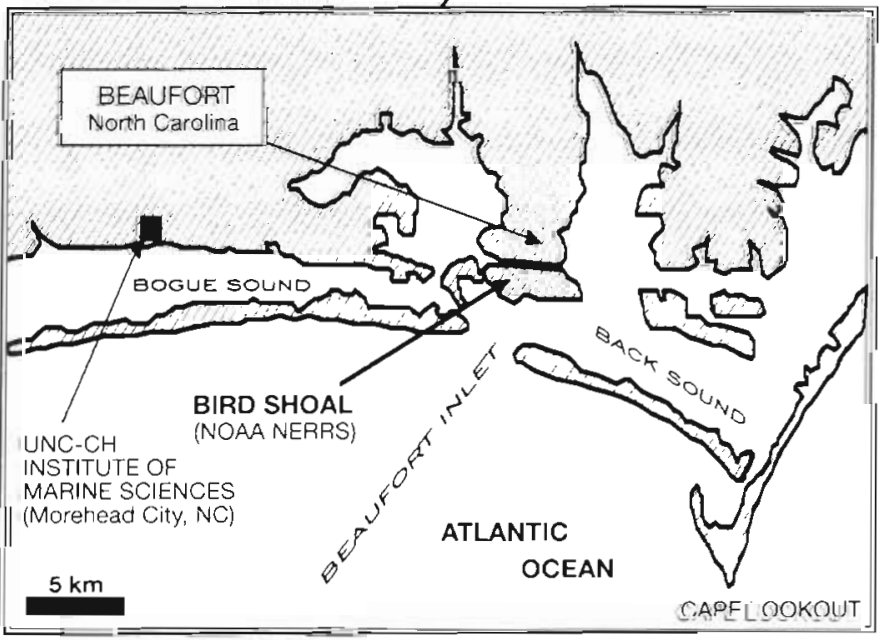

Fig. 1. Location of Bird Shoal near Beaufort, North Carolina, USA 
with wooden stakes driven into the sediment. Site 1 was located on a well-developed microbial mat that has occupied this area for at least 5 yr (Bebout et al. 1993, Paerl et al. 1993). Site 2 was also located on a well-developed mat, but this site was often exposed to waves during high tide. Site 3 was situated on what appeared to be a developing microbial mat (i.e. no distinct mat layers). Site 4 was located on a bare sand patch that had obvious sand ripples, indicative of high current flow over the area. From March 1993 to March 1994, all 4 stations were sampled monthly (except February 1994). Sampling consisted of collecting 8 cores $\left(2.54 \mathrm{~cm}^{2}\right)$ within a $3 \mathrm{~m}^{2}$ area around the site marker during low tide. Samples were returned to the laboratory and processed for photopigment analysis (see below).

Combined data from monthly diel nitrogenase activity (NA) measurements of the Bird Shoal microbial mat during 1992 and 1993 were used to provide a comparison between changes in community structure and $N_{2}$ fixation dynamics. Sections of microbial mat (50x $50 \mathrm{~cm}$ ) were removed from Bird Shoal and transported to a flowing seawater system at the Institute of Marine Sciences, University of North Carolina. At 2 h intervals over a $24 \mathrm{~h}$ period, 6 cores $\left(1.15 \mathrm{~cm}^{2}\right)$ were obtained for NA measurements (see below). These data were used to calculate total daily NA and ratios of day - to nighttime NA

Mesocosm bioassay. On 13 August 1993, 12 squares of mat $(50 \times 50 \mathrm{~cm})$ were collected during low tide from an area next to Site 1. Mat squares were obtained by cutting the mat, inserting a plexiglass plate under the mat, and lifting a $5 \mathrm{~cm}$ thick section of mat and associated sediment. Mat squares were transported to a greenhouse at the Institute of Marine Sciences, placed in plastic pans containing sterile sand, and the plexiglass plate removed from under the mat. The pans were filled with enough sand to position the mat above the edges of the pan. Three mat squares were randomly assigned to 4 fiberglass mesocosm tanks (212 l) connected to a flowing seawater system. Daily filling and draining of the tanks was necessary to simulate daily tidal exposure. Each day (10:00 to 14:00 h local time), the tanks were drained and the mats subaerially exposed for $4 \mathrm{~h}$. Submersible pumps circulated water in the tanks and provided gentle current flow over the mats. The 4 mesocosm tanks were each assigned a nutrient addition treatment consisting of a control tank (no nutrient addition), a nitrate-addition tank (100 $\mu \mathrm{M}$ $\mathrm{NaNO}_{3}$ final concentration), a phosphate-addition tank (100 $\mu \mathrm{M} \mathrm{NaH}{ }_{2} \mathrm{PO}_{4}$ final concentration), and a nitrate+ phosphate-addition tank $\left(100 \mu \mathrm{M} \mathrm{NaNO} \mathrm{N}_{3}+100 \mu \mathrm{M}\right.$ $\mathrm{NaH}_{2} \mathrm{PO}_{4}$ final concentration). These nutrient levels were ca 25 times higher than concentrations in the overlying water at Bird Shoal in August. Nutrients were added to the tank water daily. Thus, mats were chronically exposed to elevated nutrient levels throughout the incubation. Irradiance in the greenhouse was recorded using a LiCor LI-1000 data logger (model $1922 \pi$ quantum sensor). Samples for photopigment analysis and NA measurements were obtained at the initiation (time 0 ) and on Days 11 and 22 of the incubation. For photopigments, 3 cores $\left(2.54 \mathrm{~cm}^{2}\right)$ were collected from each mat square, giving a total of 9 cores for each treatment (36 total samples) for each sampling date. For NA, 2 cores $\left(1.15 \mathrm{~cm}^{2}\right)$ were obtained from each mat (24 total samples). NA rate measurements were obtained during daytime and nighttime on the 3 sampling dates.

Analytical methods. Chemotaxonomic photopigment (chlorophylls and carotenoids) concentrations were detected by high performance liquid chromatography (HPLC) (Wright et al. 1991, Millie et al. 1993). Samples for photopigment analysis were collected from microbial mats using butyrate core tubes $\left(2.54 \mathrm{~cm}^{2}\right)$. Cores were extruded, the upper $5 \mathrm{~mm}$ of mat placed in $20 \mathrm{ml}$ plastic scintillation vials, and frozen $\left(-20^{\circ} \mathrm{C}\right)$ until later analysis. At $48 \mathrm{~h}$ before analysis, $10 \mathrm{ml}$ of extraction solvent $(45 \%$ methanol, $45 \%$ acetone, $10 \%$ deionized water) was added, samples ground, sonicated for $30 \mathrm{~s}$, and returned to the freezer to allow for slow and complete extraction of photopigments (Bowles et al. 1985 Pinckney et al. 1994). Photopigment extracts (200 $\mu l)$ were separated using a Rainin Microsorb-MV $\mathrm{C}_{18}$ column $(4.6 \times 100 \mathrm{~mm}, 3 \mu \mathrm{m}$ particle size $)$ and quantified at $440 \mathrm{~nm}$ using a Shimadzu (SPD-M6a) photodiode array spectrophotometer (PDAS). The protocol for HPLC solvents and gradients is provided in Wright et al. (1991). Pigment peaks were identified by comparing retention times and absorbance spectra (380 to $670 \mathrm{~nm}$ ) with purified pigment standards. The photopigments of primary interest for this study were chlorophyll $a$, bacteriochlorophyll $a$, fucoxanthin, and zeaxanthin.

Rates of $\mathrm{N}_{2}$ fixation were estimated using the acetylene reduction assay for NA (Stewart et al. 1967, Bebout et al. 1987). Samples were obtained by removing cores $\left(1.15 \mathrm{~cm}^{2} \times 5 \mathrm{~mm}\right)$ of the mat layer. Core samples were placed in $37 \mathrm{ml}$ glass serum vials with $20 \mathrm{ml}$ of the ambient water and capped with a rubber serum stopper. Acetylene $(5 \mathrm{ml})$, freshly generated from calcium carbide, was injected into the water phase of each sample. Samples were oriented with the top of the mat facing upward and incubated under full sunlight (or darkness for night incubations) in a flowing water bath. After incubation, vials were shaken vigorously for $30 \mathrm{~s}$ to equilibrate aqueous and gas phases and $10 \mathrm{ml}$ of the gas phase was displaced into evacuated $15 \mathrm{ml}$ vials for later analysis. Samples were incubated during the day (12:00 to 14:00 h local 
time) and night (22:00 to 00:00 h). Previous studies (Bebout et al. 1987, 1993) showed that incubations during these periods represent daytime and nighttime maxima for the Bird Shoal mat. Ethylene concentrations were determined by injecting $300 \mu$ l of the headspace gas into a Shimadzu GC9A gas chromatograph (flame ionization detector, 2 m Porapak-T column, $80^{\circ} \mathrm{C}$ )

\section{RESULTS}

\section{Seasonal changes in community composition}

Chlorophyll a (chl a), an indicator of total oxygenic phototroph biomass, generally increased over the summer at all 4 sites (Fig. 2). Sites 1 and 2, characterized by a well-developed microbial mat, more than doubled the amount of chl $a$ over the 12 mo study period, indicating actively growing mat communities. Site 3 showed a reduction in chl a from April to June, followed by a gradual increase in chl a for the remainder of the period. The bare sand site, Site 4 , had lower chl a values than the other sites, ranging from

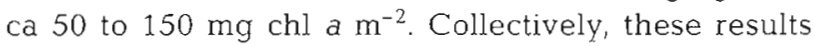
suggest that oxygenic phototroph biomass, as chl $a_{i}$ exhibited monthly variation over the seasonal cycle. However, a regular seasonal pattern was not apparent.

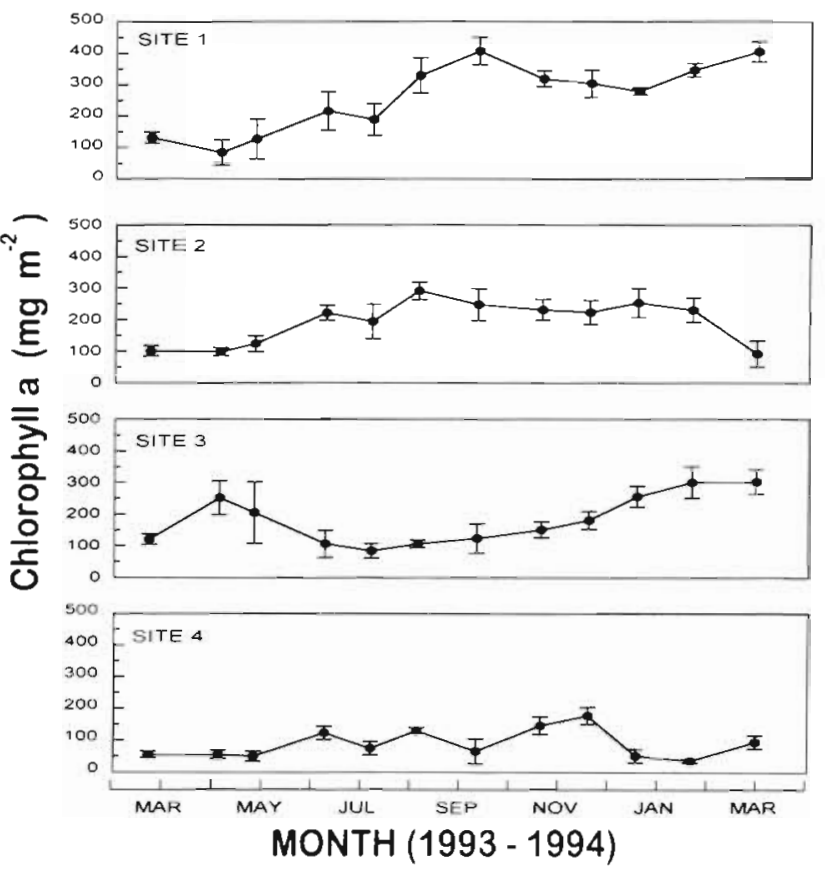

Fig. 2. Chlorophyll a concentrations (an indicator of oxygenic phototroph biomass) at the 4 sample sites on Bird Shoal from March 1993 to March 1994. Tic marks on the x-axis indicate the midpoint of each month. Values are the mean $\pm 1 S D$
Mat biomass, as chl a, showed a general increase at Sites 1 and 3 . This suggests that biomass accretion occurred and mats became thicker and more dense over time. Stochastic weather events that produce strong southwesterly winds during high tide periodically dislodge or bury microbial mats at Bird Shoal. Before the start of our survey (March 1993), Bird Shoal experienced abnormally strong southwesterly winds $\left(15\right.$ to $\left.40 \mathrm{~m} \mathrm{~s}^{-1}\right)$ and sustained low $\left(-10^{\circ} \mathrm{C}\right)$ temperatures for $3 \mathrm{~d}$. Thus, our survey may have reflected a recovery period for the Bird Shoal mats.

Similarly, monthly changes in anoxygenic phototroph biomass, indicated by bacteriochlorophyll a (bchl a), differed among the 4 sites (Fig. 3). The microbial mat sites (Sites 1 to 3) generally had higher levels of bchl a than the bare sand site (Site 4), but biomass was variable over the 12 mo at all 4 sites. The welldeveloped mat at Site 1 had consistently high bchl a levels, reaching a maxinum in January. Anoxygenic phototroph biomass did not exhibit a clear seasonal trend and was present in well-developed mats year round.

Fucoxanthin (fuco) is a carotenoid pigment characteristic of chrysophytes (diatoms), phaeophytes (brown algae), and pyrrhophytes (dinoflagellates). However, microscopic examinations of mat samples did not reveal significant quantities of phaeophytes or pyrrhophytes in these benthic communities. Therefore, fuco
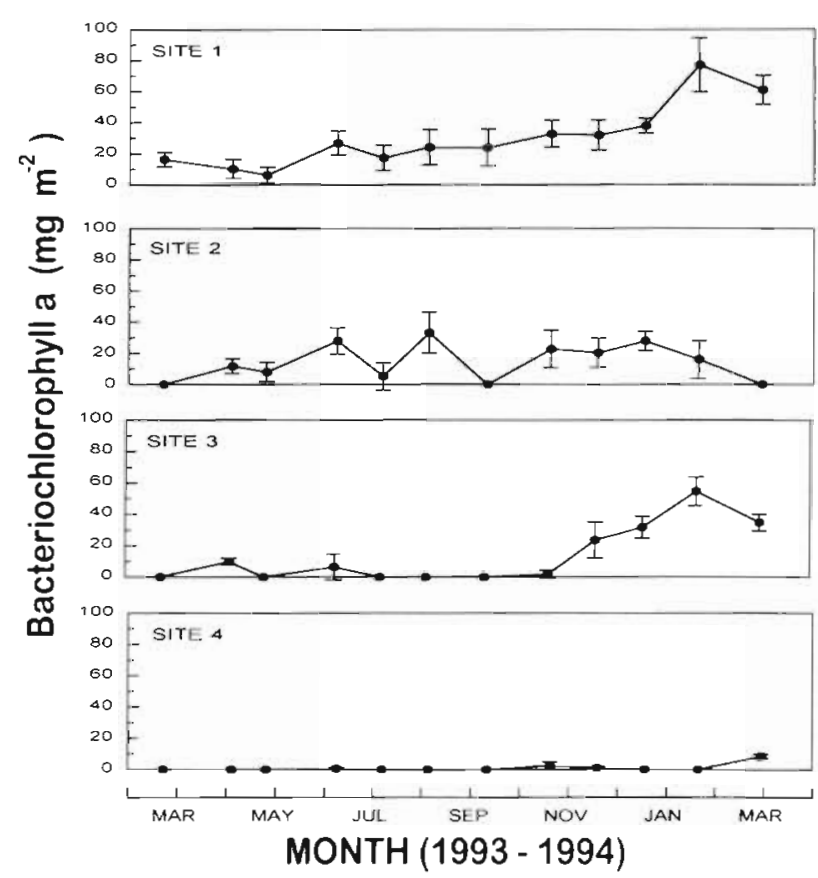

F.g. 3. Bacteriochlorophyll a concentrations (an indicator of purple sulfur bacteria biomass) at the 4 sample sites on Bird Shoal from March 1993 to March 1994. Values are the mean $\pm 1 \mathrm{SD}$ 
was used as a chemotaxonomic indicator of diatom biomass at Bird Shoal. In the microbial mats (Sites 1 to 3), diatom biomass (as fuco) generally increased in early spring (April to June), remained relatively constant from July to October, and increased during late fall and winter (November to March) (Fig. 4). At the bare sand site (Site 4 ), diatom biomass was highest in June and November. The seasonal trend for all sites was a spring and winter peak in diatom biomass, but rapid changes in diatom biomass occurred from month to month.

Cyanobacterial biomass, indicated by the carotenoid zeaxanthin (zeax), increased at Sites 1 and 3 (Fig. 5). At Site 2, cyanobacterial growth was rapid during spring and summer (March to August), followed by a decline during fall and winter. At the bare sand site (4), cyanobacterial biomass increased from March to November, then rapidly decreased during the winter. Again there was a high degree of month to month variability in cyanobacterial biomass, especially during the spring and winter.

The molar ratio zeax/fuco was used to infer changes in the relative abundance of the 2 dominant mat community components (i.e. cyanobacteria and diatoms) (Fig. 6). An increase in this ratio signifies an increase in cyanobacteria biomass relative to diatom biomass. Alternatively, a decrease in zeax/fuco indicates an increase in diatom biomass relative to
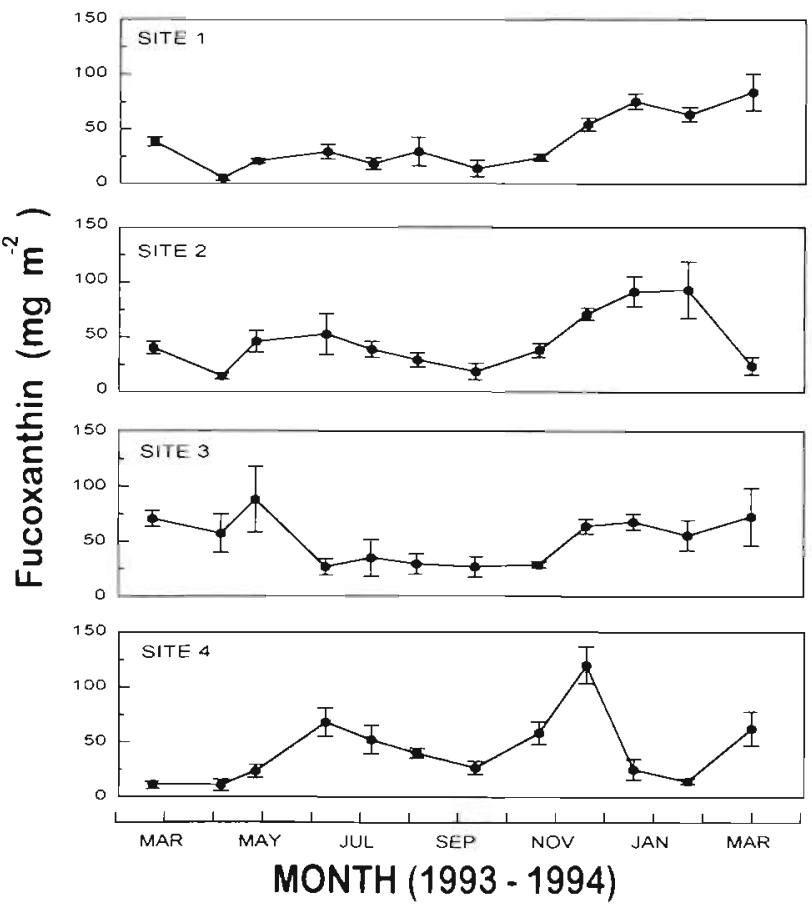

Fig. 4. Fucoxanthin concentrations (an indicator of diatom biomass) at the 4 sample sites on Bird Shoal from March 1993 to March 1994. Values are the mean \pm 1 SD
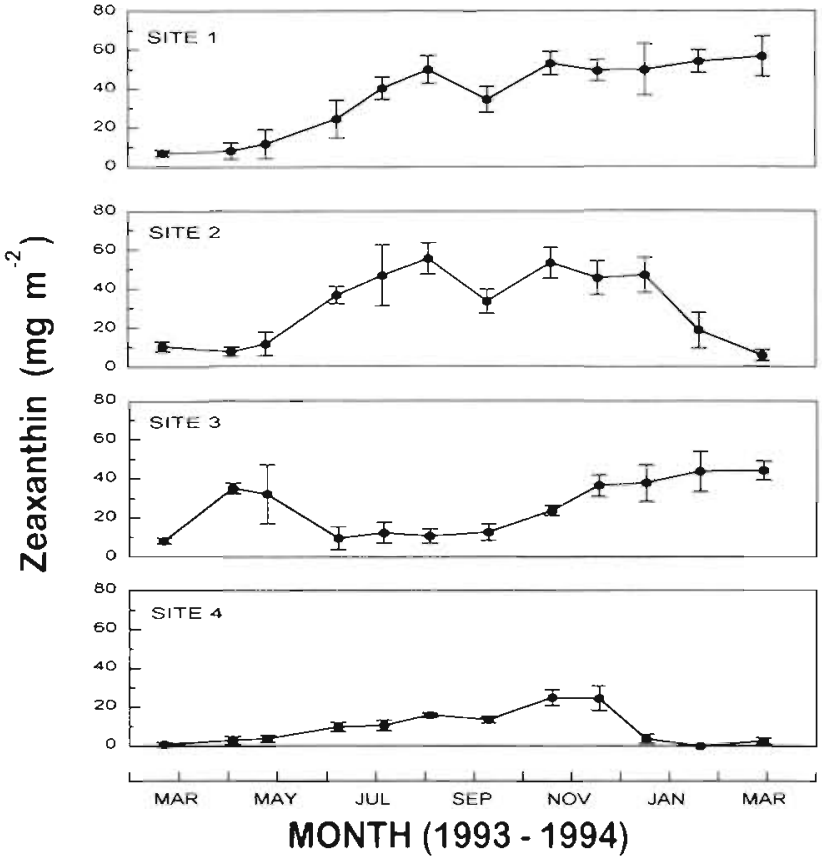

Fig. 5. Zeaxanthin concentrations (an indicator of cyanobacterial biomass) at the 4 sample sites on Bird Shoal from March 1993 to March 1994. Values are the mean \pm 1 SD
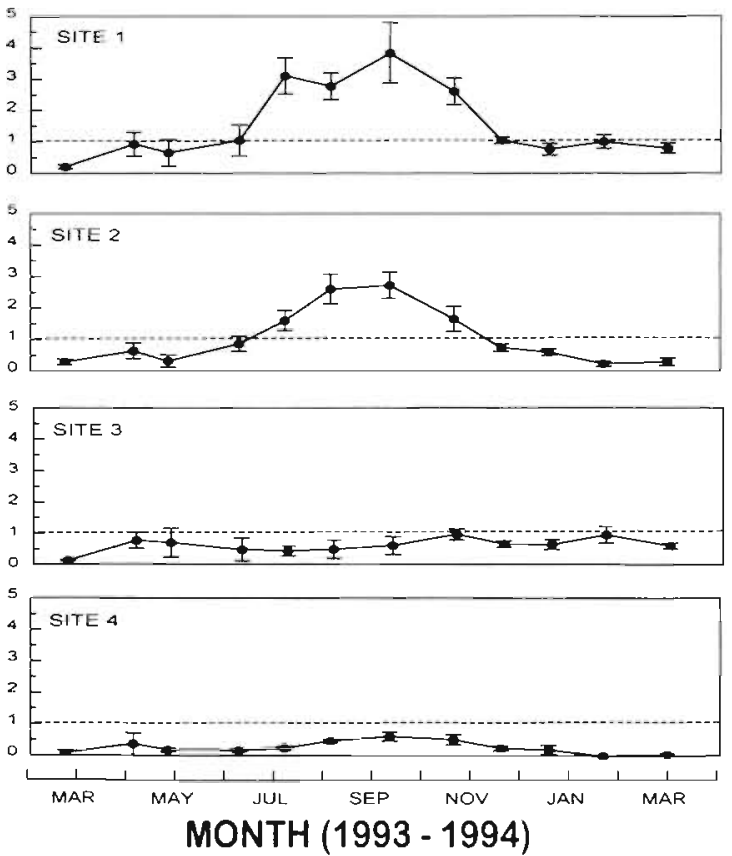

Fig. 6. Molar ratios of zeaxanthin to fucoxanthin for the 4 sites at Bird Shoal. This ratio shows changes in cyanobacterial biomass relative to diatom biomass. Increasing numbers indicate an increase in the relative abundance of cyanobacteria. Decreasing numbers indicate increasing diatom relative abundance. Values are the mean $\pm 1 \mathrm{SD}$ 


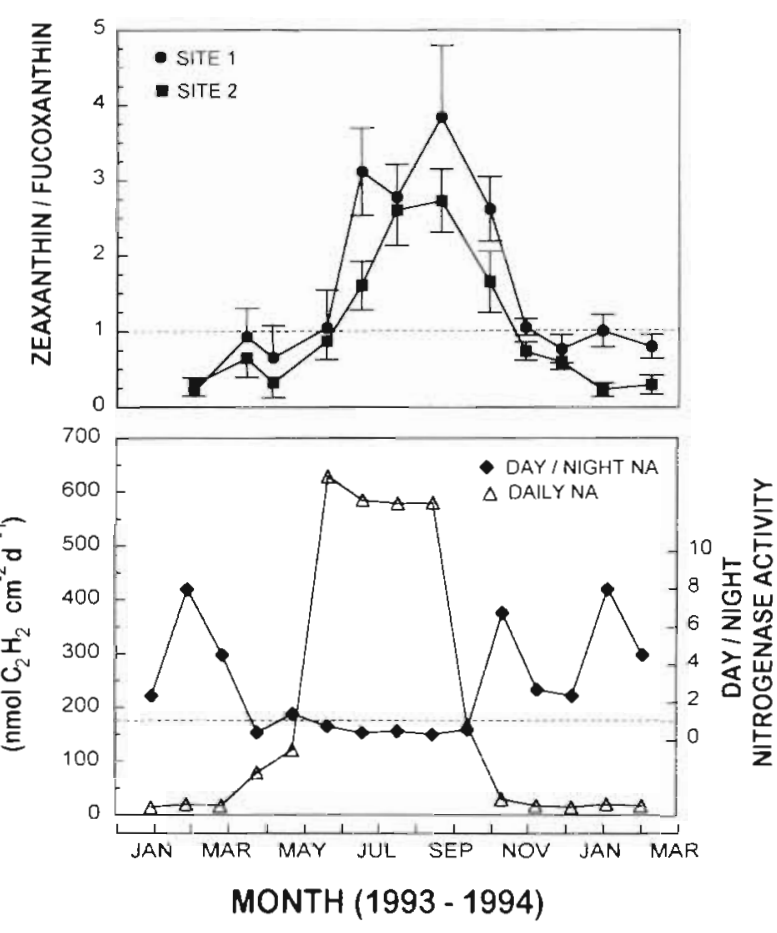

Fig. 7. Comparison of microbial mat community structure at sample Sites 1 and 2 with total daily nitrogenase activity (NA) and the ratio of day to night NA. For day/night NA ( ), values greater than 1 indicate that most NA occurs during the day. Alternatively, values less than 1 indicate that rates are higher during the night

cyanobacteria. For Sites 1 and 2, the zeax/fuco exhibited a clear seasonal trend, with the community shifting to an increase in cyanobacteria relative to diatoms during summer. During winter, diatoms increased in relative abundance. In the developing mat (Site 3), the relative abundance of diatoms and cyanobacteria remained nearly constant during the year. At the bare sand site (Site 4), there was a slight trend of increasing cyanobacterial abundance during summer and early fall (May to September). At all 4 sites, the community composition exhibited a clear seasonal shift in the relative abundance of the dominant phototrophic groups. However, community changes were more obvious at the well-developed mat sites (Sites 1 and 2).

The Bird Shoal mats showed a seasonal shift in diel $\mathrm{NA}\left(\mathrm{N}_{2}\right.$ fixation) (Fig. 7). In winter, most $\mathrm{N}_{2}$ fixation occurred during daytime. In the summer, most $\mathrm{N}_{2}$ fixation occurred at night. When compared with seasonal changes in community composition, an increase in the relative abundance of cyanobacteria seemed to be related to $\mathrm{N}_{2}$ fixation dynamics. During periods of high diatom relative abundance, most cyanobacterial/ bacterial $\mathrm{N}_{2}$ fixation occurred during the daytime. However, NA was much lower during the cooler months. Although we cannot infer a cause and effect relationship, a shift in community structure clearly coincided with a marked change in $\mathrm{N}_{2}$ fixation dynamics within the Bird Shoal microbial mat.

\section{Nutrient effects on community composition}

Weather conditions during the $22 \mathrm{~d}$ incubation period were typical for August/September and total daily irradiance averaged 50.21 Einst $\mathrm{m}^{-2} \mathrm{~d}^{-1}(\mathrm{SD}=14.11)$. Photopigment (chl $a$, fuco, and zeax) concentrations were not significantly different (ANOVA, p < 0.05) among the 4 treatments (control, nitrate, phosphate, and nitrate+phosphate) on Day 1, showing that the community composition was similar for all microbial mats at the initiation of the experiment (Fig. 8). Data for Day 11 were plotted to illustrate photopigment levels at the midpoint of the experiment. Pigment concentrations for samples collected after the 22 d incubation were statistically analyzed using a 1-way ANOVA ( 4 treatments, $\mathrm{n}=36 ; \alpha=0.01$ ). A posteriori multiple comparisons of means were achieved using the Bonferroni range test $(\alpha=0.01)$. The assumptions of ANOVA were checked before analysis. Ratio data (zeax/fuco) and NA rates were transformed using the Box-Cox transformation.

Total oxygenic phototroph biomass (chl a) increased in all treatments over the $22 \mathrm{~d}$. In general, all mats showed a net increase in biomass during the incubation, indicating that some growth occurred under all conditions. On Day 22, chl a concentrations were significantly different among the 4 treatments $(p<0.001)$. The nitrate (N) and nitrate+phosphate (NP) treatments exhibited significantly higher biomass increases (ca $150 \mathrm{mg}$ chl a m $\mathrm{m}^{-2}$ ) than the phosphate (P) and control (C) treatments (Fig. 8). These results indicate that mat community production, as a whole, was $\mathrm{N}$-limited (or possibly controlled by $\mathrm{N}$ availability) during this time of the year (August to September). Phosphate additions failed to stimulate net community growth.

Diatom abundance (as fuco) remained relatively constant in the $\mathrm{C}$ and $\mathrm{P}$ treatments. However, on Day 22, fuco concentrations were significantly different between the 4 treatments $(p<0.001$; Fig. 8$)$. The $N$ and NP treatments showed a greater increase ( +90 and $+163 \%$, respectively) in diatom biomass relative to the control. Mat diatom growth was enhanced by nitrate additions and appeared to be $N$ limited. The NP treatment showed the highest increase in fuco, suggesting that phosphate may have been limiting at high nitrate concentrations. Phosphate additions alone did not enhance diatom growth relative to the control. 

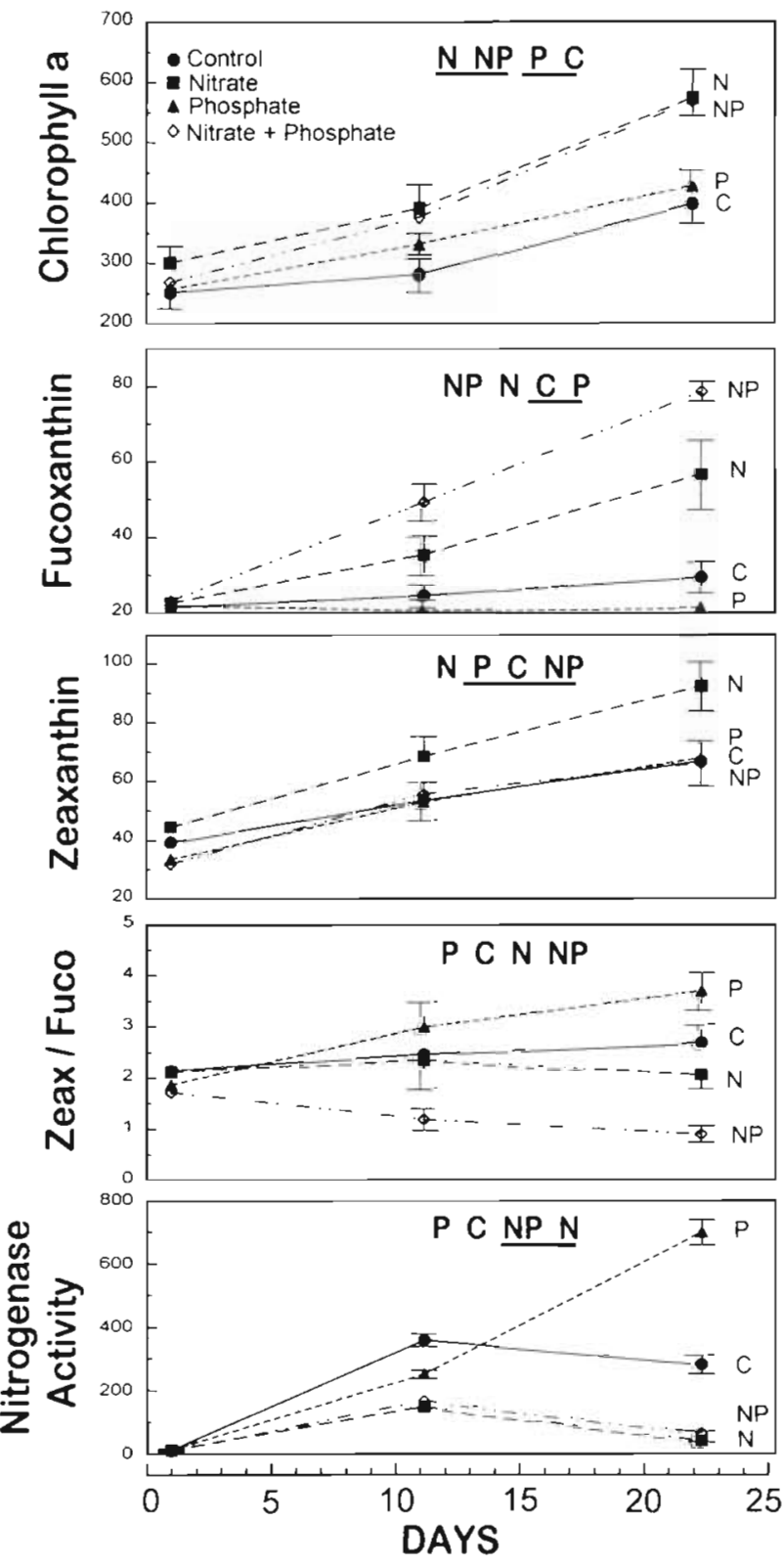

Fig. 8. Results of the mesocosm nutrient addition bioassay. Results of a posteriori comparisons of means for Day 22 are

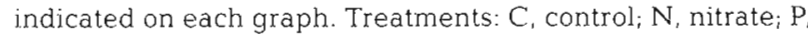
phosphate; NP, nitrate+phosphate. Letters connected by a common underline indicate that the means were not significantly different $(p<0.01)$. The order (left to right) for letters reflects highest to lowest mean values. For clarity, the identities of symbols are labeled for Day 22. Units are $\mathrm{mg} \mathrm{m}^{-2}$ for pigment concentrations and nmol $\mathrm{C}_{2} \mathrm{H}_{2} \mathrm{~cm}^{-2} \mathrm{~d}^{-1}$ for nitrogenase activity. Values are the mean $\pm 1 \mathrm{SD}$

Cyanobacterial abundance, indicated by zeax concentrations, also showed a significant treatment effect after $22 \mathrm{~d}(\mathrm{p}<0.001$; Fig. 8). Although $\mathrm{P}$ and NP treatments were not significantly different from the control, the $\mathrm{N}$ treatment showed a significant increase $(+38 \%)$ in cyanobacterial biomass. These results suggest that, like diatoms, mat cyanobacterial growth was $\mathrm{N}$-limited during this time of the year. However, the addition of nitrate+phosphate did not result in a significant increase in cyanobacterial biomass. Because the $\mathrm{N}$ treatment did exhibit increased growth, the implication is that the combination of nitrate+phosphate had a negative impact on cyanobacterial growth.

The zeax/fuco molar ratio, which shows changes in the abundance of cyanobacteria relative to diatoms, was used to indicate changes in the community composition over time. After $22 \mathrm{~d}$, zeax/fuco was significantly different among the treatments ( $p<0.001$; Fig. 8). The $P$ treatment resulted in the highest increase $(+34 \%)$ in zeax/fuco. The $N$ and NP treatments resulted in zeax/fuco values lower $(-28$ and $-108 \%$, respectively) than the control. These results suggest that an increase in $\mathrm{P}$ concentration favors growth of cyanobacteria relative to diatoms. Nitrate additions led to a small increase $(+28 \%)$ in the relative abundance of diatoms. However, the addition of nitrate+phosphate appeared to favor diatom growth, resulting in a marked change in mat community composition.

Mat samples were examined microscopically to determine if the species composition changed during the incubation. The same cyanobacterial species (Microcoleus chthonoplastes and Lyngbya aestuarii) were present at the beginning and end. Although not quantified, diatom abundance seemed higher in the $\mathrm{N}$ and NP treatments after $22 \mathrm{~d}$. The pigment data, coupled with microscopy, suggest that although the relative abundance of phototrophic community dominants (i.e. diatoms and cyanobacteria) changed over the 22 d period, species composition was similar.

Day and night NA measurements were used to estimate total daily $(24 \mathrm{~h}) \mathrm{NA}$ rates (Fig. 8). Measurements of NA were very low on Day 1 (ca $10 \mathrm{nmol}$ $\mathrm{C}_{2} \mathrm{H}_{4} \mathrm{~cm}^{-2} \mathrm{~d}^{-1}$ ) but were not significantly different among the treatments $(\mathrm{p}>0.05)$. Prior to the start of the experiment, the mats were exposed to low in situ irradiances due to cloud cover and inclement weather conditions. Exposure to high irradiance is a prerequisite for nighttime cyanobacterial $\mathrm{N}_{2}$ fixation (Bebout et al. 1993) and the absence of sufficient light exposure may explain the low rates on Day 1. NA measurements on Day 22 showed a significant treatment effect ( $p<0.001$ ). The $P$ treatment exhibited the highest NA rates and was ca 2.5 times higher than the control. The $\mathrm{N}$ and NP treatments had NA rates that were significantly lower ( -84 and $-75 \%$, respectively) than the control. When compared with the community composition data (zeax/fuco; Fig. 8), the treatments that showed an increase in the relative abundance of cyanobacteria (C and P) also showed significant 
increases in total daily NA. A community shift toward higher diatom abundance ( $N$ and NP) coincided with a decrease in NA.

\section{DISCUSSION}

Benthic microalgae can rapidly (minutes to hours) photoacclimate to changing light environments (Falkowski \& LaRoche 1991). Photoacclimation may be achieved by altering the relative concentrations of primary (chl a) and accessory photopigments (carotenoids) in the light-harvesting complex (Falkowski \& LaRoche 1991). Observed changes in the concentrations of photopigments may reflect photoacclimation responses under stressful conditions (photoinhibition, photorespiration) rather than changes in the relative abundance of respective phototrophs (Paerl 1984, Wilhelm \& Manns 1991). However, the accessory photopigments (zeaxanthin, fucoxanthin) we used for chemotaxonomic markers are relatively conservative with respect to photoacclimation responses (Rowan 1989, Millie et al. 1993). The results of the nutrient addition bioassay experiment provide support for this approach. Large changes in photopigment concentrations were documented even though the microbial mats were exposed to identical light environments. Although the chemotaxonomic photopigment method for quantifying changes in the relative abundance of respective phototrophs has limitations, the method does provide an alternative approach for quantifying changes in community structure.

The collective results of monthly measurements of the Bird Shoal mats suggest that both total biomass (i.e. standing stock ) and the relative biomass of community components underwent marked changes on both monthly and seasonal scales. Community composition changes also corresponded with patterns and amount of daily $\mathrm{N}_{2}$ fixation. When NA was low, diatom biomass increased. The mechanisms of interactions between mat community composition and $\mathrm{N}_{2}$ fixation were not examined in this study. However, our results suggest that interactions (whether direct or indirect) do indeed exist and have profound effects on mat community structure and $\mathrm{N}_{2}$ fixation dynamics. Changes in the phototrophic community may potentially have cascading effects on microfaunal and meiofaunal communities, resulting in seasonal shifts in the trophic structure of the microbial food web within mats.

During the nutrient addition bioassays, chl a increased over the $22 \mathrm{~d}$ incubation period in all treatments, with nitrate additions promoting the most growth. Summarizing the results of several nutrient addition bioassays on a variety of benthic microbial mat types, Paerl et al. (1993) found that short-term (5 d) incubations generally failed to show nutrient enhancement of growth. However, they suggested that longer incubations may have been necessary to detect nutrient addition effects on microbial mats. Although detectable increases in phototrophic biomass occurred by Day 11 in our bioassays, clear differences were not evident until after $22 \mathrm{~d}$ of exposure to enhanced nutrient levels. Bioassay results suggest that relatively long (>15 d) incubations are indeed necessary to detect nutrients potentially limiting temperate intertidal microbial mat community growth.

Cyanobacterial and diatom growth proved to be $\mathrm{N}$ limited. This $\mathrm{N}$-limitation is in part alleviated by $\mathrm{N}_{2}$ fixation in cyanobacteria-dominated mats, while diatoms are reliant on externally supplied combined $\mathrm{N}$. The combination of nitrate+phosphate further enhanced diatom growth, suggesting nutrient colimitation at high nitrate levels. For cyanobacteria, the combined nitrate+phosphate additions did not significantly enhance growth. One explanation for the absence of a significant increase in cyanobacteria in the NP treatment may be that the ability of cyanobacteria to use the nutrients was compromised by a rapid increase in diatom abundance. The absence of a cyanobacterial response may be attributed to more efficient nutrient uptake/utilization by diatoms or an indirect effect of shading by a dense canopy of motile benthic diatoms. Phosphate was not limiting for either diatom or cyanobacterial growth. Nutrient additions resulted in a measurable shift in the relative abundance of the 2 dominant phototrophic community components. Phosphate additions favored increases in cyanobacteria while nitrate+phosphate additions resulted in an increase in the relative abundance of diatoms. Fong et al. (1993) noted a similar phosphate response for cyanobacterial mats from shallow coastal lagoons in southern California, USA. Nitrate additions, although enhancing community growth, did not result in an alteration of community structure. The ability of cyanobacteria to supplement their combined $\mathrm{N}$ requirements by $\mathrm{N}_{2}$ fixation may explain why the community shifts toward cyanobacterial dominance at enhanced phosphate concentrations. When exposed to enhanced nitrate and phosphate levels, the ability of cyanobacteria to fix $\mathrm{N}_{2}$ does not offer a competitive advantage and the relative abundance of diatoms increases. This phenomenon may partially explain why cyanobacteria-dominated microbial mat communities are generally restricted to low-nutrient (oligotrophic) environments. At high nutrient ( $\mathrm{N}$ and $\mathrm{P}$ ) levels, diatoms may be competitive dominants.

Phosphate additions, which resulted in an increase in cyanobacterial relative abundance, also resulted in a significant increase in NA. Phosphate-enhanced NA has also been reported for microbial mats in the 
Bahamas and Tomales Bay, California (Paerl et al. 1993, Pinckney et al. 1995). These results provide further support for the importance of cyanobacteria in mat $\mathrm{N}_{2}$ fixation dynamics. High nitrate and nitrate+ phosphate concentrations appear to negatively affect $\mathrm{N}_{2}$ fixation. When nitrate is present, the demand for combined $\mathrm{N}$ is supplied by exogenous $\mathrm{N}$ sources, reducing the need for energetically expensive $\mathrm{N}_{2}$ fixation to provide combined $\mathrm{N}$.

For phytoplankton communities, low N/P supply ratios result in $\mathrm{N}$-limited growth and favor the formation of $\mathrm{N}_{2}$-fixing cyanobacterial populations (Flett et al. 1980, Howarth et al. 1988, Stockner \& Shortreed 1988, Smith 1990). The Bird Shoal microbial mats seem. to conform to this generalization and provide a benthic analog for what is normally considered a water column process. P was not limiting for the mats, but both diatoms and cyanobacteria exhibited N-limited growth. Low $N$ supply for diatoms and a high P supply for $\mathrm{N}_{2}$-fixing cyanobacteria allowed cyanobacteria to proliferate in this estuarine environment.

The results of the nutrient addition bioassay illustrate one possible mechanism that may be responsible for shifts in the community structure of in situ microbial mat communities. At Bird Shoal, nutrient availability, whether from localized $\mathrm{N}_{2}$ fixation or from external sources (i.e. water column, regeneration, atmospheric $\mathrm{N}$ deposition), may be the driving force behind monthly and seasonal shifts in mat phototrophic community composition. Microbial mats exposed to high nutrient levels quickly respond with changes in the relative abundance of cyanobacteria and diatoms. In the nutrient bioassay, biomass doubled and $\mathrm{N}_{2}$ fixation tripled in $3 \mathrm{wk}$ when supplied with inputs of nitrate and phosphate. These responses to nutrient inputs are well within the measured month to month changes documented for the in situ mat community at Bird Shoal.

Growth in this temperate cyanobacterial mat community appears to be $\mathrm{N}$-limited (at least during summer). Eutrophic conditions, especially when nitrate, ammonium, and phosphate levels are sufficiently high, may offer a competitive advantage for diatoms and result in a reduction of cyanobacterial biomass. The results of this study show that manipulative experiments, together with quantitative assessments of community composition based on chemotaxonomic photopigments, can provide useful insights into the mechanisms that relate microbial mat community structure and function to environmental constraints, including nutrient limitation and seasonal climatic changes.

Acknowledgements. We thank D. Millie, R. Zingmark, C Currin and 2 anonymous reviewers for helpful comments on previous drafts. K. Howe aided in HPLC analyses and M. Piehler provided logistical and analytical support. Funding for this study was provided by NSF grants OCE 9012496 and 9115706 and NOAA/North Carolina Sea Grant Projects R/MER23 and REMP-1 to H.W.P. Support for J.L.P. was provided by an appointment to the Global Change Distinguished Postdoctoral Fellowships sponsored by the US Department of Energy, Office of Health and Environmental Research, and administered by the Oak Ridge Institute for Science and Education

\section{LITERATURE CITED}

Bebout B, Fitzpatrick M, Paerl H (1993) Identification of the sources and energy for nitrogen fixation and physiological characterization of nitrogen-fixing members of marine microbial mat community. Appl environ Microbiol 59: $1495-1503$

Bebout B, Paerl H, Crocker K, Prufert L (1987) Diel interactions of oxygenic photosynthesis and $\mathrm{N}_{2}$ fixation (acetylene reduction) in a marine microbial mat community. Appl environ Microbiol 53:2353-2362

Bowles H, Paerl H, Tucker J (1985) Effective solvents and extraction periods employed in phytoplankton carotenoid and chlorophyll determinations. Can J Fish Aquat Sci 42:1127-1131

Falkowski P, LaRoche J (1991) Acclimation to spectral irradiance in algae. J Phycol 27:8-14

Flett R, Schindler D, Hamilton R, Campbell N (1980) Nitrogen fixation in Canadian Precambrian Shield lakes. Can J Fish Aquat Sci 37:494-505

Fong P, Zedler J, Donohoe R (1993) Nitrogen vs. phosphorus limitation of algal biomass in shallow coastal lagoons. Limnol Oceanogr 38:906-923

Gieskes W (1991) Algal pigment fingerprints: clue to taxonspecific abundance, productivity and degradation of phytoplankton in seas and oceans. In: Demers S (ed) Particle analysis in oceanography. Springer-Verlag, Berlin, p 61-99

Howarth R, Lane J, Cole J (1988) Nitrogen fixation in freshwater, estuarine, and marine ecosystems. 1 Rates and importance. Limnol Oceanogr 33:669-687

Jorgensen B, Des Marais D (1988) Optical properties of benthic photosynthetic communities: fiber optic studies of cyanobacterial mats. Limnol Oceanogr 33:99-113

Klein B, Riaux-Gobin C (1991) Algal pigment diversity in coastal sediments from Kerguelen (sub-Antarctic Islands) reflecting local dominance of green algae, euglenoids and diatoms. Polar Biol 11:439-448

Millie D, Paerl H, Hurley J (1993) Microalgal pigment assessments using high performance liquid chromatography: a synopsis of organismal and ecological applications. Can J Fish Aquat Sci 50:2513-2527

Paerl H (1984) Cyanobacterial carotenoids: their roles in maintaining optimal photosynthetic production among aquatic bloom forming genera. Oecologia 61:143-149

Paerl H, Joye S, Fitzpatrick M (1993) Evaluation of nutrient limitation of $\mathrm{CO}_{2}$ and $\mathrm{N}_{2}$ fixation in marine microbial mats. Mar Ecol Prog Ser 101:297-306

Palmisano A, Cronin S, D'Amelio E, Munoz E, Des Marais D (1989a) Distribution and survival of lipophilic pigments in a laminated microbial mat community near Guerro Negro, Mexico. In: Cohen Y, Rosenberg E (eds) Microbial mats. Am Soc Microbiol, Washington, DC, p 138-152

Palmisano A, Summons R, Cronin S, Des Marais D (1989b) Lipophilic pigments from cyanobacterial (blue-green algal) and diatom mats in Hamelin Pool, Shark Bay, Western Australia. J Phycol 25:655-661 
Pinckney J, Paerl H, Reid R, Bebout B (1995) Ecophysiology of stromatolitic microbial mats, Stocking Island, Exuma Cays, Bahamas. Microb Ecol 29:19-37

Pinckney J, Papa R, Zingmark R (1994) Comparison of highperformance liquid chromatographic, spectrophotometric, and fluorometric methods for determining chlorophyll a concentrations in estuarine sediments. J microbiol Meth $19: 59-66$

Rowan K (1989) Photosynthetic pigments of algae. Cambridge Univ Press, New York

Smith V (1990) Nitrogen, phosphorus, and nitrogen fixation in lacustrine and estuarine ecosystems. Limnol Oceanogr 35: $1852-1859$

Stàl L, van Gemerden H, Krumbein W (1985) Structure and development of a benthic microbial mat. FEMS Microbiol Lett 31:111-125

Stewart W, Fitzgerald G, Burris R (1967) In situ studies of $\mathrm{N}_{2}$ fixation using the acetylene reduction technique. Proc Natl Acad Sci USA 58:2071-2078

Stockner J, Shortreed K (1988) Response of Anabaena and

This article was presented by G. W. Thayer (Senior Editorial Advisor), Beaufort, North Carolind, USA
Synechococcus to manipulation of nitrogen:phosphorus ratios in a lake fertilization experiment. Limnol Oceanogr 33: $1348-1361$

Whitton B, Potts M (1982) Marine littoral. In: Carr N, Whitton $B$ (eds) The biology of cyanobacteria. Blackwell Sci Publ Co, Oxford, p 515-542

Wilhelm C, Manns L (1991) Changes in pigmentation of phytoplankton species during growth and stationary phaseconsequences for reliability of pigment-based methods of biomass determination. J appl Phycol 3:305-310

Wilhelm C, Rudolph I, Renner W (1991) A quantitative method based on HPLC-aided pigment analysis to monitor structure and dynamics of the phytoplankton assemblage - a study from Lake Meerfelder Maar (Eifel, Germany). Arch Hydrobiol 123:21-35

Wright S, Jeffrey S, Mantoura R, Llewellyn C, Bjørnland T, Repeta D, Welschmeyer N (1991) An improved HPLC method for the analysis of chlorophylls and carotenoids from marine phytoplankton. Mar Ecol Prog Ser 77: $183-196$

Manuscript first received: September 12, 1994 Revised version accepted: February 7, 1995 